\title{
Article \\ Utilisation of Mining Waste from the Steel Industry, Ladle Furnace Slags, as a Filler in Bituminous Mixtures of Continuous Grading
}

\author{
Francisco Javier Nebreda-Rodrigo, Juan María Terrones-Saeta *(D), Jorge Suárez-Macías (D), \\ Evaristo Rafael Moreno-López, Francisco Antonio Corpas-Iglesias (D) and Carmen Martínez-García (i)
}

check for updates

Citation: Nebreda-Rodrigo, F.J.; Terrones-Saeta, J.M.; Suárez-Macías, J.; Moreno-López, E.R.;

Corpas-Iglesias, F.A.;

Martínez-García, C. Utilisation of Mining Waste from the Steel Industry, Ladle Furnace Slags, as a Filler in Bituminous Mixtures of Continuous Grading. Metals 2021, 11, 1447. https://doi.org/10.3390/met11091447

Academic Editor: Valentina Colla

Received: 12 August 2021

Accepted: 10 September 2021

Published: 13 September 2021

Publisher's Note: MDPI stays neutral with regard to jurisdictional claims in published maps and institutional affiliations.

Copyright: (c) 2021 by the authors. Licensee MDPI, Basel, Switzerland. This article is an open access article distributed under the terms and conditions of the Creative Commons Attribution (CC BY) license (https:/ / creativecommons.org/licenses/by/ $4.0 /)$.
Research Group TEP-222 "Materials and Mining Engineering”, Higher Polytechnic School of Linares, Scientific and Technological Campus of Linares, University of Jaen, 23700 Linares, Spain; fjnr0002@red.ujaen.es (F.J.N.-R.); jsuarez@ujaen.es (J.S.-M.); erml0001@red.ujaen.es (E.R.M.-L.); facorpas@ujaen.es (F.A.C.-I.); cmartin@ujaen.es (C.M.-G.)

* Correspondence: terrones@ujaen.es

\begin{abstract}
Road construction is an activity that involves a large consumption of raw materials, with the consequent high environmental impact. For this reason, various research projects are being developed in which waste is used as a raw material for bituminous mixtures. This avoids the extraction of raw materials, reduces the environmental impact and reduces greenhouse gas emissions. In this research, the incorporation of ladle furnace slag as a filler for continuous grading bituminous mixtures was evaluated. Firstly, the ladle furnace slag was chemically and physically characterised and its suitability for use as a filler was determined in accordance with the regulations. Subsequently, bituminous mixtures were conformed with the slag and also with commercial fillers, calcareous and hornfels, in order to compare the results. Finally, the physical properties, Marshall stability and the effect of water were determined with the immersion-compression test on all families of samples. The results showed that the mixes conformed with ladle furnace slag had higher Marshall stability, less variation due to the effect of water and acceptable physical properties. Consequently, the suitability of utilisation of these slags in bituminous mixtures could be confirmed.
\end{abstract}

Keywords: mining waste; aggregate treatment plants; steel industry; ladle furnace slag; bituminous mixtures; pavements; road construction; sustainability; circular economy

\section{Introduction}

The construction and maintenance of roads is an essential activity for the economic development of a country. Roads are essential communication links for a nation, reporting social and economic benefits. In addition, most goods transport is carried out by road, being essential over short and medium distances.

Nevertheless, the construction sector, and more specifically the road sector, is one of the most contaminating sectors in existence today [1]. This fact mainly due to the high demand for raw materials, as well as the use of poorly-optimised industrial processes, which consume large quantities of solid fuels [2,3].

Based on the above, it is logical to think that these infrastructures should be built and maintained with more sustainable processes and materials, since their execution is required [4]. For this reason, the outdated scheme of the linear economy in which materials are extracted and products are manufactured, used and at the end of their working life are discarded, should be avoided. Research in this sector should be carried out in the field of the circular economy [5], in other words, to use waste as raw material for new products, to develop more optimised industrial processes for production, to extend the working life of the product as much as possible and finally, after its deterioration, to use this material as raw material for other products [6,7]. This type of material utilisation scheme presents a 
sustainable aspect of material production and analyses all phases of the product, closing material flows [8] and avoiding waste disposition in landfills, as well as the extraction of new raw materials.

Within the field of the circular economy and of the construction sector, new production systems have been developed in which the consumption of solid fuels and, consequently, $\mathrm{CO}_{2}$ emissions are optimised and controlled to the maximum [9]. These new processes for the manufacture of bituminous mixtures use bitumen emulsions to conform the bituminous mixtures at ambient temperature and, therefore, avoid the continuous heating of the aggregates. It should be noted that bituminous mix is the main element of most roads, being the material in which most natural and economic resources are invested.

Another side of the circular economy arises from the use of waste or industrial byproducts with the aim of minimising the extraction of raw materials [10], avoiding the dumping of this waste in landfills and obtaining a product of similar quality [11]. There are different lines of research framed within this concept, with several examples in which by-products from other industries have been successfully used. Among the waste used are ceramic dust [12], biomass ash [13], recycled glass [14], construction and demolition waste [15], recycled crumb rubber [16], etc. In most cases, similar properties were obtained as traditionally manufactured bituminous mixtures without prejudice to the final quality of the material.

At the same time, it should be highlighted that in order to use an industrial by-product in a bituminous mixture that consumes significant amounts of raw materials, the waste must comply with a series of qualities. On the one hand, it is essential to study it in order to evaluate its physical and chemical characteristics, and with this evaluation it is possible to adapt the waste to the function that it can best perform within the bituminous mix [17]. Furthermore, it must be determined which polluting elements it possesses that could cause environmental pollution [18]. In addition, the waste produced must have certain physical and chemical characteristics that are maintained over time, i.e., that do not vary in different production batches. Otherwise, the properties of the final material would be modified and could produce negative qualities of the final material. This is the case, for example, with sewage sludge [19]. In this by-product, the concentration of polluting elements, organic matter, physical properties, etc., varies depending on the city and even the months of the year.

Therefore, and as discussed above, this investigation assesses the use of ladle furnace slag for the production of hot mix asphalt for roads. Ladle furnace slag is a waste product of the steel industry which is produced in considerable quantities. These slags are derived from the steel refining process and have no current use [20]. In addition, their basic $\mathrm{pH}$ and small particle size make this waste an environmentally harmful material that must be treated and reused.

There have been few investigations in which ladle furnace slag was used to create new materials. Most research is carried out in the field of concretes, evaluating the partial replacement of cement with ladle furnace slag or as filler [21-23]. All these investigations have shown that ladle furnace slag has very interesting cementitious characteristics [24,25].

Consequently, in this research, and given the small particle size of the ladle furnace slag, the slag was used as a filler for continuous grading bituminous mixtures. These bituminous mixtures are those usually used on medium-low traffic roads, and even on higher traffic roads as base courses. Furthermore, these continuous grading mixes have a suitable void content and are called AC16S according to Spanish regulations.

To corroborate the suitability of the ladle furnace slag as filler for the above-mentioned bituminous mixture, hornfels aggregates were used as both coarse and fine aggregate. These aggregates have acceptable strength and physical properties for use. In order to compare the advantages and disadvantages of the use of ladle furnace slag filler in the aforementioned bituminous mix, the same type of mix was compared with the aggregate's own filler (hornfels), with calcareous filler and ladle furnace slag filler. 
For the evaluation, firstly the chemical and physical characteristics of the ladle furnace slag were analysed through various tests. Subsequently, the detailed mixture was blended with the hornfels aggregate and with the various fillers mentioned. These families of bituminous mixtures were blended with increasing percentages of bitumen from $4 \%$ to $5 \%$ of the mixture. The properties of the bituminous mixtures obtained were evaluated through the Marshall test and the immersion-compression test. In this manner it could be objectively determined what the advantages were in mechanical terms of the incorporation of the ladle furnace slag as a filler.

Finally, the results were analysed, and the optimum combination of materials was obtained for the three families of bituminous mixtures blended with the three types of filler mentioned. The analysis of the results showed a higher Marshall stability of the bituminous mixtures blended with ladle furnace slag, as well as a higher void content. At the same time, a higher single compressive strength with and without water immersion of the test samples was obtained, reflecting excellent compatibility of the ladle furnace slag with the bitumen, as well as the cementitious properties of the slag.

\section{Materials and Methods}

This section describes the materials used in this research, as well as the scientific methodology followed to confirm the suitability of ladle furnace slag as filler in bituminous mixtures.

\subsection{Materials}

The materials used in this research are subsequently defined in order to be able to reproduce the tests described in this research and to corroborate the results.

These materials are mainly natural aggregates and bitumen. In turn, the ladle furnace slag is also defined and will later be characterised through various physical and chemical tests. Therefore, this section describes the general properties of the materials, as well as their origin.

\subsubsection{Ladle Furnace Slag}

The ladle furnace slag (LFS) used in this research came from the area of Andalucía, Spain. These slags were derived from the steel industry dedicated to the manufacture of steel from mainly scrap.

The manufacture of steel consists of two main stages, the melting stage and the refining stage. The first stage is carried out in electric arc furnaces, where the raw materials are melted, and where oxidation, dephosphorisation and the formation of foaming slag occur. At the end of this stage, electric arc furnace slag (EAFS) is extracted.

The molten liquid from the electric arc furnace at the end of the process and after removing the mentioned slag is transferred to the ladle furnace and is continuously agitated by blowing inert gas, usually argon. At this stage, deoxidation, desulphurisation and decarburisation of the steel take place. At the end of the process, ladle furnace slag is obtained.

Ladle furnace slag has a fairly small particle size, so it is suitable for use as a filler in bituminous mixtures. However, this slag was sieved in this investigation by the $0.063 \mathrm{~mm}$ sieve to obtain the desired particle size fraction. It was then dried in an oven for $24 \mathrm{~h}$ at a temperature of $105 \pm 2{ }^{\circ} \mathrm{C}$. The material obtained was conserved by avoiding exposure to humidity, and this grading fraction was used in all the methods of this investigation.

\subsubsection{Hornfels Aggregate}

The hornfels aggregate used in this research was from the region of Andalucía, Spain. The hornfels rocks are contact metamorphic rocks, very hard, of high mechanical resistance and capable of resisting glacial action.

Its main mineralogical composition is formed by quartz, graphite, biotite, iron oxide and feldspars. 
Hornfels rocks take on the role within the analysed bituminous mixtures of coarse and fine aggregates, and even in one of the families act like a filler. However, the adhesion of hornfels aggregates to bitumen is usually poor, so they are not usually used as fillers, and fillers that forms a quality mastic capable of withstanding traffic loads are used. Usually calcareous filler.

\subsubsection{Calcareous Filler}

The filler is an aggregate with a small particle size that is added to the bituminous mix to form, together with the bitumen and other additives, a quality mastic capable of withstanding the traction loads of traffic.

The calcareous filler used was also from the area of Andalucía, Spain. This filler is derived from limestone rocks, that is, sedimentary rocks composed mainly of calcium carbonate.

The use of calcareous aggregates for roads is common. However, due to the low mechanical resistance of these aggregates as well as their reduced resistance to the polishing by the tyre, their use is restricted to medium-low traffic roads. However, their adhesion with bitumen is much higher than that of silicate rocks, so they are usually used as filler for the formation of a quality mastic that envelops the ophite aggregates.

\subsubsection{Bitumen}

The bitumen used in this type of bituminous mixture is a bitumen designated by Spanish and European regulations as B 60/70. This bitumen is characterised to be hard due to the low penetration it has, the penetration rate being between the numbers reflected in its nomenclature. It is commonly used for hot mix asphalt in hot regions, as is the case in Spain. In this way, problems of plastic deformation derived from the use of bitumens with higher penetrations are avoided. The bitumen data sheet is detailed in Table 1.

Table 1. Technical specifications of the bitumen used.

\begin{tabular}{ccccc}
\hline Characteristics & Unit & Standard & Min & Max \\
\hline \multicolumn{4}{c}{ Fresh binder } \\
\hline Penetration $\left(25^{\circ} \mathrm{C}\right)$ & $0.1 \mathrm{~mm}$ & ASTM D5 & 60 & 70 \\
Ductility & $\mathrm{cm}$ & ASTM D113 & 100 & - \\
Solubility & $\%$ & ASTM D2042 & 99.0 & - \\
Flash point & ${ }^{\circ}$ & ASTM D92 & 450 & - \\
\hline Retained penetration & Resistance to Hardening 163 ${ }^{\circ} \mathrm{C}$ (ASTM D1754) & - \\
Ductility & $\%$ & ASTM D5 & 47 & - \\
\hline
\end{tabular}

\subsection{Methodology}

The methodology developed in this research consisted of a series of logically ordered tests. These tests reflect a series of results that were analysed to corroborate the initial hypothesis. This initial hypothesis consisted of the evaluation of ladle furnace slag as a filler for the manufacture of continuous grading bituminous mixtures.

First of all, the ladle furnace slags were physically and chemically characterised to corroborate their suitability as a filler for bituminous mixtures, as well as to detect contaminant elements that could damage the final product and should therefore be monitored in the process.

Next, the grading curve of the hot mix asphalt with continuous grading was defined. This bituminous mixture is called AC16S according to Spanish standards. Subsequently, different families of mixtures were defined with hornfels aggregates and ladle furnace slag filler, calcareous filler or hornfels filler. For each family, different percentages of bitumen were established to evaluate the optimal combination of materials through the Marshall test. 
Finally, the optimal combination of materials was defined and the tests were repeated in order to corroborate the results defined above. At the same time, the immersioncompression test was carried out in order to quantify different properties of the bituminous mixtures made up of each family with the optimum combination of materials.

The following sections describe in greater depth the three stages into which this research is subdivided, namely characterisation of ladle furnace slag; conformation and testing of bituminous mixtures; and the optimal combination of materials.

\subsubsection{Characterisation of Ladle Furnace Slag}

The initial stage in any research carried out with waste is the physical and chemical characterisation of the waste in order to evaluate its suitability for use in the final material, as well as the detection of possible critical points that could damage the process. In this investigation, the main focus is on obtaining appropriate physical properties of ladle furnace slag so that it can be used as a filler. At the same time, the chemical composition reflects the possible behaviour of the slag, as well as the existence of contaminating elements that could cause significant environmental pollution or negative characteristics of the final material.

The first of the tests carried out for chemical characterisation was elemental analysis. This test determines the percentage of carbon, nitrogen, hydrogen and sulphur in the waste, thanks to the analysis of the gases produced during the ignition of the sample at $950 \pm 5{ }^{\circ} \mathrm{C}$. This test was performed with LECO's TruSpec Micro equipment (TruSpec Micro, LECO, St. Joseph, MI, USA), in order to evaluate the presence of organic matter, nitrogen, carbon, etc., in the sample. In addition, and with the aim to determine and quantify the existence of the elements of higher atomic weight, the X-ray fluorescence test was carried out with the ADVANT'XP+ commercial equipment (ADVANT'XP+, Thermo Fisher, Waltham, MA, USA). At the same time, an X-ray diffraction test was carried out to identify the main chemical compounds in the ladle furnace slag. This chemical test was carried out with the commercial X'Pert PRO equipment (X'Pert PRO, PANalytical, Malvern, UK). Finally, to evaluate the surface of the ladle furnace slag particles, the samples were analysed by scanning electron microscopy. More specifically, the electron microscope used was a commercial (FESEM) MERLIN (Carl Zeiss, Oberkochen, Germany).

On the other hand, and in order to evaluate the physical properties of the ladle furnace slag, a laser diffraction particle size analysis was carried out to corroborate the size of the particles evaluated. This test, carried out with Mastersizer 2000LF commercial equipment (Mastersizer 2000LF, PANalytical, Malvern, UK), used laser light diffraction technology for the analysis of the wet prepared sample. In addition, the particle density (standard UNE-EN 1097-7) was calculated to determine whether volumetric corrections are necessary; bulk density in kerosene (standard UNE-EN 1097-3), to quantify whether it is a pulverulent material; and the plasticity index (standard UNE-EN ISO 17892-12), to detect the presence of plastic materials that could damage the final product.

The tests described above made it possible to objectively evaluate the quality of the ladle furnace slag used to blend bituminous mixtures, as well as the critical points to which special attention should be paid in order to achieve a suitable end product.

\subsubsection{Blend of Bituminous Mixtures and Tests}

Once the ladle furnace slag was characterised, different hot mix asphalts with continuous grading were blended. The mixture developed is called AC16S according to Spanish regulations, Orden FOM/2523/2014. This type of bituminous mixture is the most common of those applied to roads, as they are used for medium or low traffic roads, and even as a base course on major traffic roads. The mixture has a continuous grading provided by the hornfels coarse and fine aggregates as well as for filler. The above-mentioned standard defines a grading envelope into which the grading curve defined by the different aggregates must fit. In this research, the grading curve defined in Figure 1 was used for the three families of bituminous mixtures detailed below. 


\section{AC 16 S GRADING CURVE}

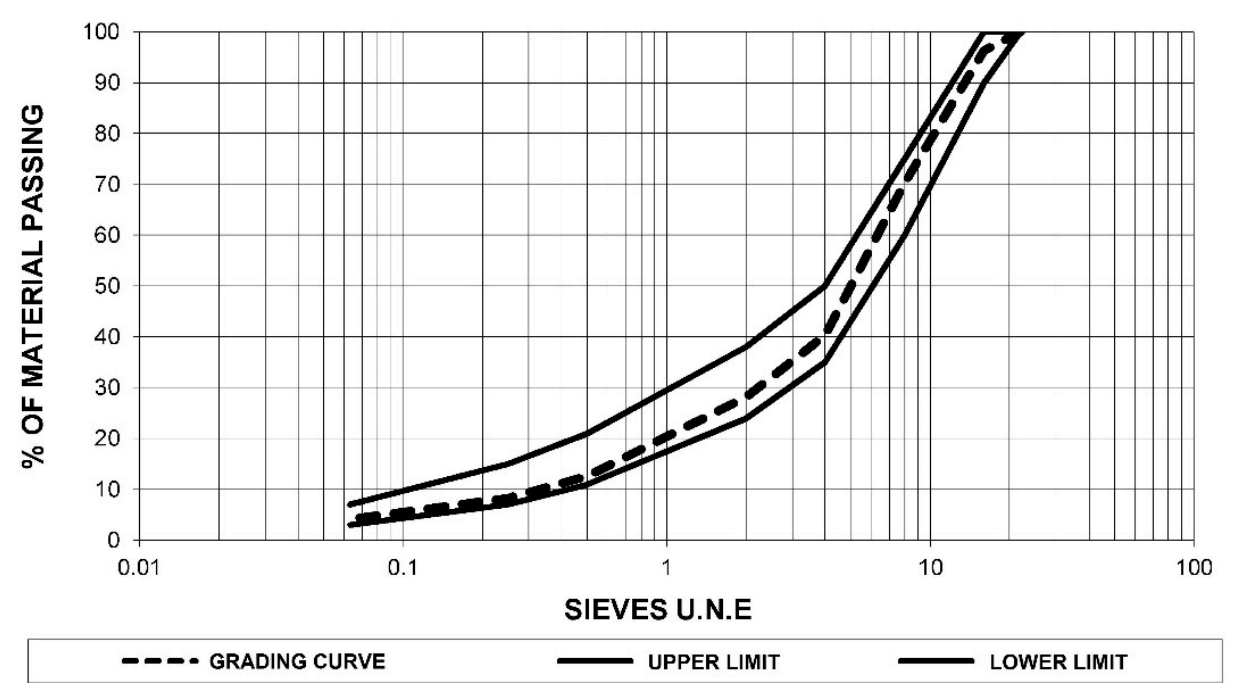

Figure 1. Grading AC16S grading curve referring to the grading envelope defined by the standard ORDER FOM/2523/2014.

The grading curve defined in Figure 1 is that used in all the families of bituminous mixtures produced. The coarse and fine aggregate was hornfels aggregate. This type of aggregate has excellent mechanical properties; however, with smaller particle sizes, its adhesion with the bitumen is not of good quality. In turn, the filler used was ladle furnace slag, calcareous filler and hornfels filler from the coarse aggregate itself. Table 2 shows the materials conforming to the families of bituminous mixtures developed.

Table 2. Denomination and conforming elements of each family of bituminous mixtures made with different fillers.

\begin{tabular}{cccc}
\hline Samples Groups & HF & CF & SF \\
\hline Coarse aggregate & Hornfels aggregate & Hornfels aggregate & Hornfels aggregate \\
Fine Aggregate & Hornfels aggregate & Hornfels aggregate & Hornfels aggregate \\
Filler & Hornfels aggregate & Calcareous filler & Ladle Furnace slag \\
Bitumen & B 60/70 & B 60/70 & B 60/70 \\
\hline
\end{tabular}

The families detailed in Table 2 were blended with different percentages of bitumen to the mix, from $4 \%$ to $5 \%$ in $0.25 \%$ increments of bitumen. A total of five groups of test samples were made with different percentages of bitumen for each family, with 6 test samples being made for each group to obtain statistically analysable data.

To make the samples of the different groups of samples, all materials were previously heated to a temperature of $180 \pm 5^{\circ} \mathrm{C}$. The materials were stirred in an automatic planetary mixer for $5 \mathrm{~min}$. After this time, homogenisation of the mixtures was observed and they were compacted at a temperature of $140 \pm 5^{\circ} \mathrm{C}$. The compacting was carried out in accordance with the UNE-EN 12697-30 standard with 50 blows per side of the specimens. Once the specimens had been tempered, they were stripped of their moulds for subsequent tests.

The samples made of each group and each family were tested to determine their physical properties. The physical properties evaluated were bulk density, according to the UNE-EN 12697-6 standard, and maximum density, according to the UNE-EN 12697-5 standard. With the average values of each group of samples, the void characteristics was calculated. This parameter is essential in bituminous mixtures, as it provides drainage characteristics, surface roughness and even noise absorption by the contact of the tyre with the pavement. In turn, the voids characteristics in the mixture was calculated in accordance 
with the UNE-EN 12697-8 standard, this being an essential parameter for understanding the combination of materials in the bituminous mixture.

Once the physical properties had been evaluated, we proceeded to calculate the plastic deformations that could be produced by the incorrect bitumen content in the asphalt mixture. These properties were quantified through the Marshall test, standard UNE-EN 12697-14. This test consists of calculating the mechanical resistance, where the specimen was subjected to high temperature, thus evaluating the influence of the bitumen and, consequently, the optimum content of the binder.

\subsubsection{Determination of Optimal Material Combinations}

Once the physical properties and Marshall stability of all the sample groups had been determined, the optimum combination of materials was obtained for each of the families. Since the percentage of coarse aggregate, fine aggregate and filler was set beforehand, the percentage of bitumen providing the highest strength was evaluated in this process. To this end, once the Marshall test was carried out for each group of samples of each family, the results were evaluated, and the percentage of binder that obtained the best mechanical properties was selected graphically.

Once the optimum combination of materials for each family was determined, the test samples were made again for the optimum bitumen percentage, and the simple compressive strength was tested with and without immersion in accordance with the Spanish standard NLT-162/00. This test evaluated the compressive strength of the developed of bituminous mixture families as well as the compatibility of the bitumen with the aggregates.

\section{Results and Discussion}

This section describes the results obtained from the tests mentioned in the methodology, as well as the partial discussion of the results. The logical and orderly process of the test involves the evaluation of the final hypothesis, this being the confirmation of the goodness of the ladle furnace slag as a filler in continuous grading hot mix asphalts. In the following sections, the tests and discussions are detailed in the three sections described in the methodology.

\subsection{Characterisation of Ladle Furnace Slag}

Initially, the physical properties and chemical characterisation of the ladle furnace slag had to be determined in order to objectively evaluate its suitability for use as a filler in bituminous mixtures.

Chemical characterisation is composed of different tests, one of the main ones being elemental analysis. This test determines the percentage of carbon, nitrogen, hydrogen and sulfur that exists in the ladle furnace slag. The results of this test are shown in Table 3.

Table 3. Elemental analysis of ladle furnace slag.

\begin{tabular}{ccccc}
\hline Sample & Nitrogen, $\%$ & Carbon, $\%$ & Hydrogen, $\%$ & Sulfur, $\%$ \\
\hline LFS & $0.007 \pm 0.001$ & $3.405 \pm 0.068$ & $1.386 \pm 0.026$ & $0.000 \pm 0.001$ \\
\hline
\end{tabular}

The elemental analysis of the ladle furnace slag reflected the composition of an inorganic material, as expected. There were low percentages of nitrogen and sulfur. This is positive, because if there were high percentages of these elements, the concentration of these elements in the leachate should be quantified to avoid environmental pollution. Low percentages of carbon and hydrogen were present, corresponding these elements with high probability to the carbonation and hydration of some chemical compounds present in the ladle furnace slag.

For the determination of the rest of the chemical elements, an X-ray fluorescence test was carried out. The results of this test are detailed in Table 4 . 
Table 4. Results of the X-ray fluorescence of ladle furnace slag.

\begin{tabular}{ccc}
\hline Compound & Wt., \% & Est. Error \\
\hline $\mathrm{CaO}$ & 40.19 & 0.25 \\
$\mathrm{MgO}$ & 19.38 & 0.20 \\
$\mathrm{SiO}_{2}$ & 12.49 & 0.17 \\
$\mathrm{Al}_{2} \mathrm{O}_{3}$ & 7.29 & 0.13 \\
$\mathrm{Fe}_{2} \mathrm{O}_{3}$ & 2.38 & 0.08 \\
$\mathrm{MnO}$ & 0.936 & 0.047 \\
$\mathrm{~S}$ & 0.548 & 0.027 \\
$\mathrm{TiO}_{2}$ & 0.486 & 0.024 \\
$\mathrm{BaO}$ & 0.240 & 0.012 \\
$\mathrm{Na}_{2} \mathrm{O}$ & 0.118 & 0.042 \\
$\mathrm{Cr}_{2} \mathrm{O}_{3}$ & 0.1100 & 0.0055 \\
$\mathrm{Cl}$ & 0.0833 & 0.0042 \\
$\mathrm{SrO}$ & 0.0733 & 0.0037 \\
$\mathrm{ZnO}_{\mathrm{K}_{2} \mathrm{O}}$ & 0.0681 & 0.0034 \\
$\mathrm{ZO}_{2}$ & 0.0506 & 0.0025 \\
$\mathrm{~V}_{2} \mathrm{O}_{5}$ & 0.0425 & 0.0021 \\
$\mathrm{P}$ & 0.0179 & 0.0017 \\
$\mathrm{CuO}_{\mathrm{NiO}}$ & 0.0138 & 0.0012 \\
$\mathrm{PbO}$ & 0.0117 & 0.0010 \\
$\mathrm{Nb}_{2} \mathrm{O}_{5}$ & 0.0082 & 0.0011 \\
$\mathrm{MoO}_{3}$ & 0.0048 & 0.0010 \\
$\mathrm{Co}_{3} \mathrm{O}_{4}$ & 0.0046 & 0.0006 \\
$\mathrm{SeO}_{2}$ & 0.0028 & 0.0009 \\
& 0.0021 & 0.0009 \\
& 0.0012 & 0.0005 \\
\hline
\end{tabular}

The X-ray fluorescence test of ladle furnace slag reflected an elemental composition consisting mainly by calcium, magnesium, silicon, aluminium and iron. This chemical composition was directly derived from the formation process of the ladle furnace slag, with calcium, magnesium, silicon and aluminium added to the furnace to produce the refining of the liquid from the electric arc furnace. In turn, the percentage of iron corresponded to the material that is treated in the production industry, iron being the main element of steel. The low percentages of heavy metals ensure that there are no contaminating leachates in the final product in contact with water, thus avoiding environmental pollution. It should be noted that even though the composition was presented as the oxides of different elements through the X-ray fluorescence test, this does not imply that these oxides exist in the material, since this test only considers the elemental composition and not chemical compounds. To determine the main chemical compounds that form the ladle furnace slag, the X-ray diffraction test was carried out. This test is shown in Figure 2.

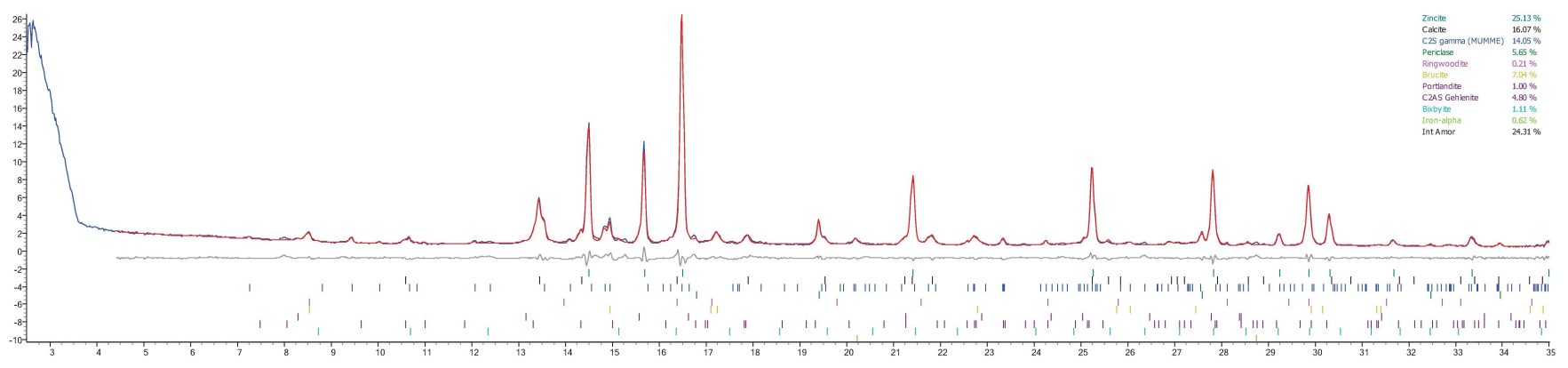

Figure 2. Results of X-ray diffraction of ladle furnace slag.

The X-ray diffraction test of the slag showed clear results after the analysis of the diffractogram. The high content of amorphous and non-diffractive material in the sample was remarkable. Calcite, olivine and periclase were identified as the main phases. In addi- 
tion, we found in a lower proportion dicalcium silicate, tricalcium silicate and magnesium silicates. Therefore, its composition based on calcite and silicates directly provides the cementitious properties obtained from the use of ladle furnace slag. These cementitious properties were confirmed by various authors. It should be pointed out that there were no magnesium oxides in high proportion, so that no problems of expansiveness could occur in the slag, since the main compound was the much more stable magnesium silicate and without the aforementioned problems.

In turn, scanning electron microscopy showed the surface texture of the ladle furnace slag at high magnifications, as seen in Figure 3.
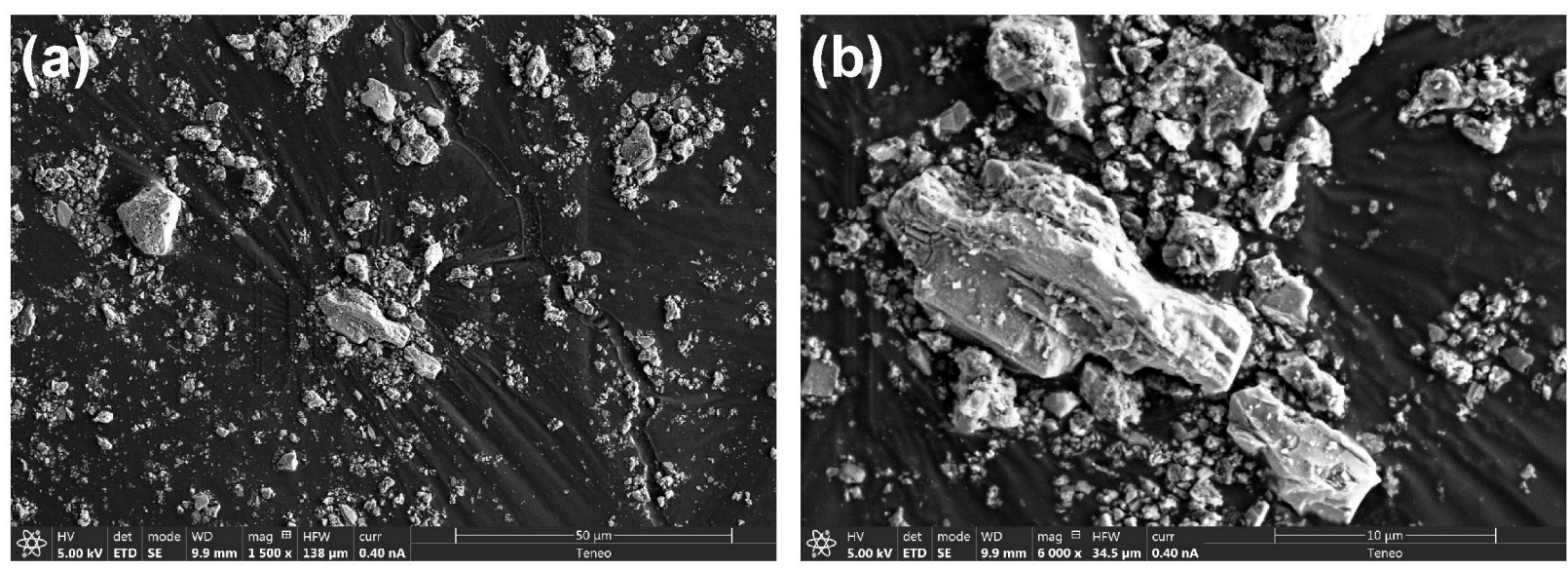

Figure 3. Scanning electron microscope image of ladle furnace slag with the secondary option: (a) $1500 \times$; (b) $6000 \times$.

Figure 3, corresponding to the image of the ladle furnace slag with scanning electron microscopy, shows the small size of the particles, with particles of different sizes coexisting but, in all cases, less than 100 micrometres. A high specific surface area could be observed in the texture of the particles, which were very similar to cement or lime particles. In turn, through scanning electron microscopy, we were able to analyse the chemical composition of different particles, corroborating the reflected chemical composition of ladle slag in $\mathrm{X}$-ray fluorescence and X-ray diffraction tests. Because the quality of the compositional analysis with scanning electron microscopy does not possess high sensitivity compared to the chemical tests mentioned, the data were represented. However, it should be noted that the chemical elements in the particles were the same as those determined in the previous chemical tests.

On the other hand, and in order to obtain the particle size accurately to evaluate the suitability of ladle furnace slag for use as filler, laser diffraction particle size analysis was carried out. The results of this test are detailed in Figure 4.

The laser diffraction particle size analysis of the ladle furnace slag reflected a particle size of less than 100 microns. In turn, particles with sizes around 30 microns were the ones that existed in the sample in the highest percentage. This particle size is ideal for use as a filler, as it is small enough to absorb an adequate percentage of bitumen. However, the conformation of bituminous mixes with ladle furnace slag will reflect whether or not an adequate percentage of bitumen is actually absorbed to produce quality mixes.

Once the particle size of the ladle furnace slag had been determined and its chemical suitability assessed, another vital important physical test was carried out. These tests are the particle density, the bulk density in kerosene and the plasticity index. The results of these tests are shown in Table 5. 


\section{LADLE FURNACE SLAG GRADING CURVE}

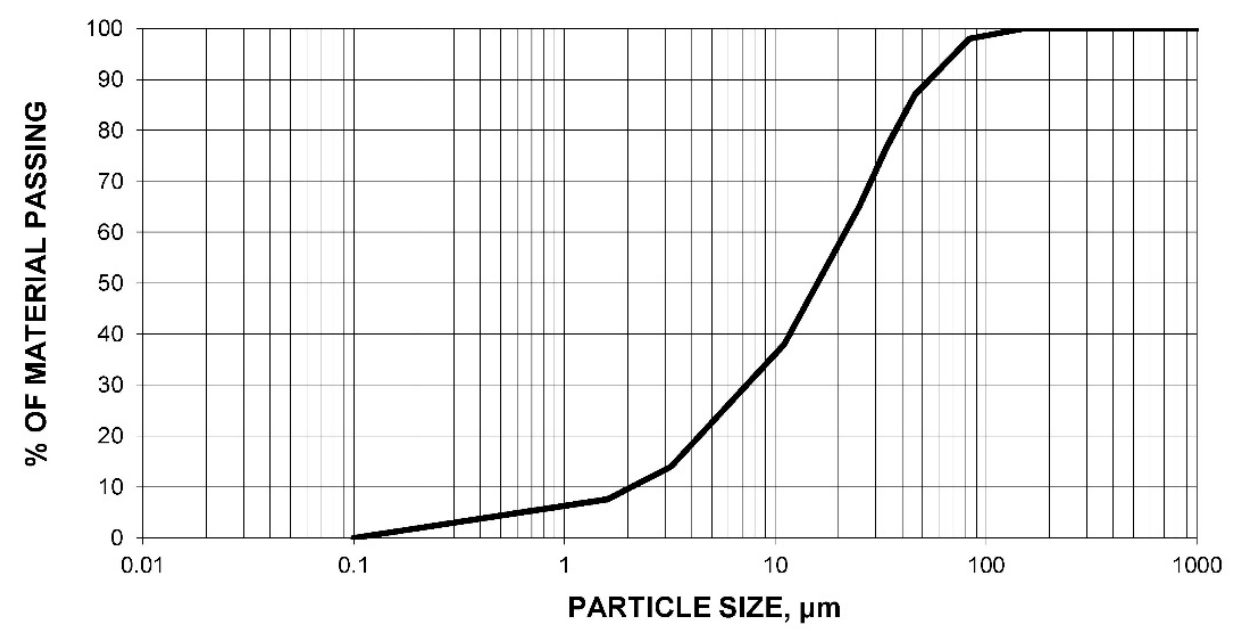

Figure 4. Laser diffraction particle size analysis of ladle furnace slag particles.

Table 5. Density and plasticity tests for the fine portion of ladle furnace slag.

\begin{tabular}{ccc}
\hline Test & Standard & Value/Unit \\
\hline Particle density & UNE-EN 1097-7 & $2.71 \pm 0.07 \mathrm{t} / \mathrm{m}^{3}$ \\
Bulk density & UNE-EN 1097-3 & $0.75 \pm 0.01 \mathrm{t} / \mathrm{m}^{3}$ \\
Plasticity index & UNE 103103/UNE 103104 & No plasticity \\
\hline
\end{tabular}

The particle density of the ladle furnace slag did not differ from the density of a commercial filler, namely $2650 \mathrm{~kg} / \mathrm{m}^{3}$. Therefore, it was not necessary to make volumetric corrections for mass proportioning as is the case of the electric arc furnace slags. At the same time, the bulk density in kerosene was within the limits set by the regulations, which reflects the fact that ladle furnace slag is not a pulverulent material that could impair its proportioning in the factory or absorb high percentages of bitumen. Finally, no plasticity was found in ladle furnace slag mainly due to its chemical composition consisting of silicates and lime. Therefore, no problems of expansiveness were obtained in the final material.

\subsection{Conformed of Bituminous Mixtures and Tests}

Once the physical properties and chemical composition of the ladle furnace slag had been evaluated, the different families of bituminous mixtures detailed in Table 2 were manufactured. These families were blended according to the procedure described in the methodology with different groups of samples for each family of mixtures. The groups of samples of each family differed in the percentage of bitumen added, varying from $4 \%$ to $5 \%$ of mixture in increments of $0.25 \%$.

The different groups of samples were initially tested for their physical properties. Firstly, the apparent density of the bituminous mixtures blended for each family and with different percentages of bitumen was analysed. The results of the bulk density are shown in Figure 5. 


\section{BULK DENSITY VS. \% BITUMEN}

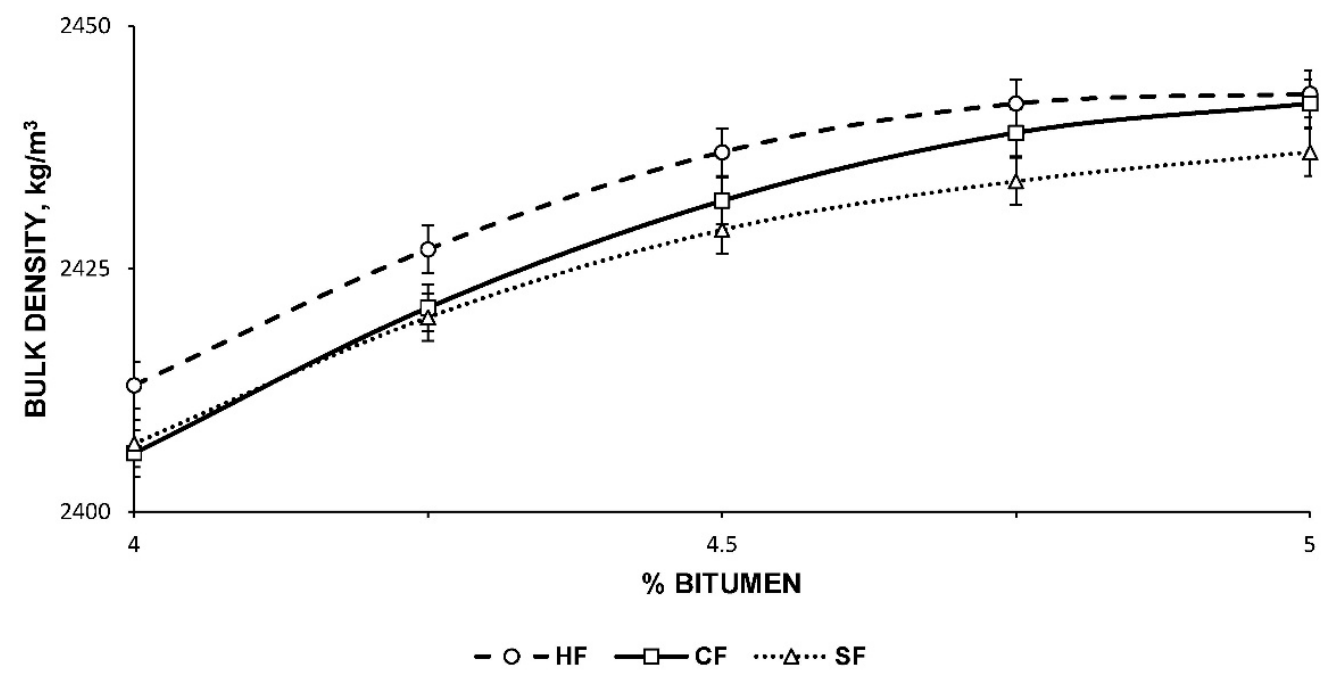

Figure 5. Bulk density of the HF, CF and SF families of bituminous mixtures according to the percentage of bitumen.

As can be seen, the bulk density of the family of bituminous mixtures blended with ladle furnace slag fillers was lower than that of other mixtures. The family of bituminous mixtures blended with hornfels aggregate was the one that represented the highest bulk density, obtaining similar values to the families of bituminous mixtures blended with calcareous filler in the highest percentages of bitumen. This physical property, together with the maximum density, influenced the voids content in mixtures. Therefore, the results of the maximum density of the families of mixtures were studied, as detailed in Figure 6.

MAXIMUM DENSITY VS. \% BITUMEN

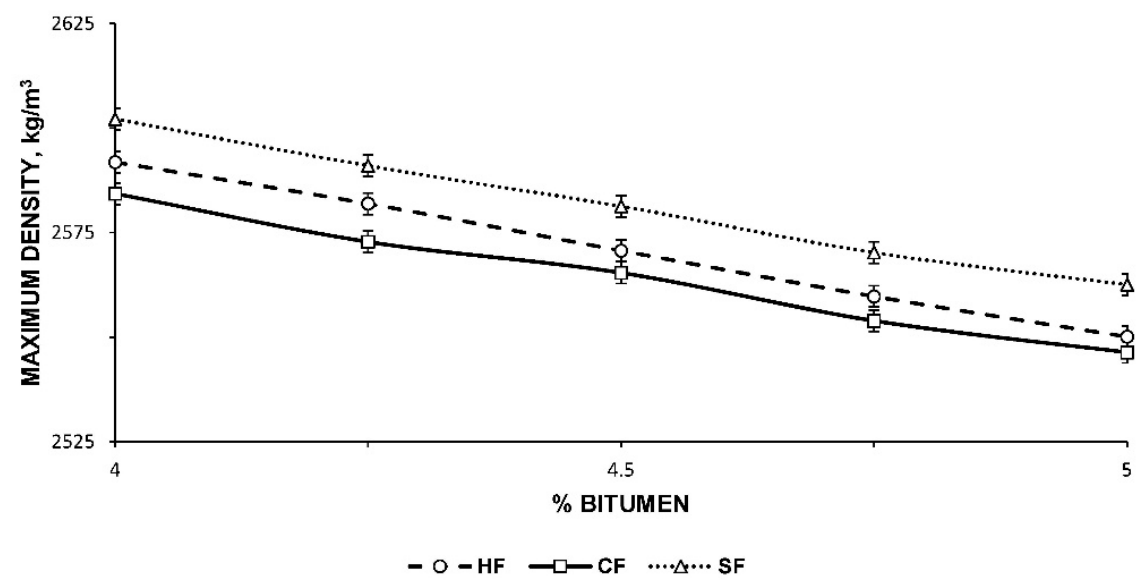

Figure 6. Maximum density of the HF, CF and SF families of bituminous mixtures according to the percentage of bitumen.

The maximum density, as shown in Figure 6, was higher for bituminous mixtures blended with ladle furnace slag. With lower density than this family were the bituminous mixtures made with hornfels aggregate and, finally, the mixtures with calcareous aggregate. This maximum density was conditioned by the density of the filler, since at the same percentage of bitumen and using the same coarse and fine aggregate, different densities were obtained. However, the difference between the maximum densities of the three families was negligible, but the greater density of the ladle furnace slag could be distinguished with respect to the density of the hornfels filler and calcareous filler.

Both the maximum density and the bulk density directly conditioned the void content in the mixture. This physical property had a significant influence on the quality of the 
bituminous mix obtained, which is why its results are very important to analyse. The results of the voids content in mix for the three families blended with the three different fillers mentioned and with different percentages of bitumen are detailed in Figure 7.

VOID CONTENT VS. \% BITUMEN

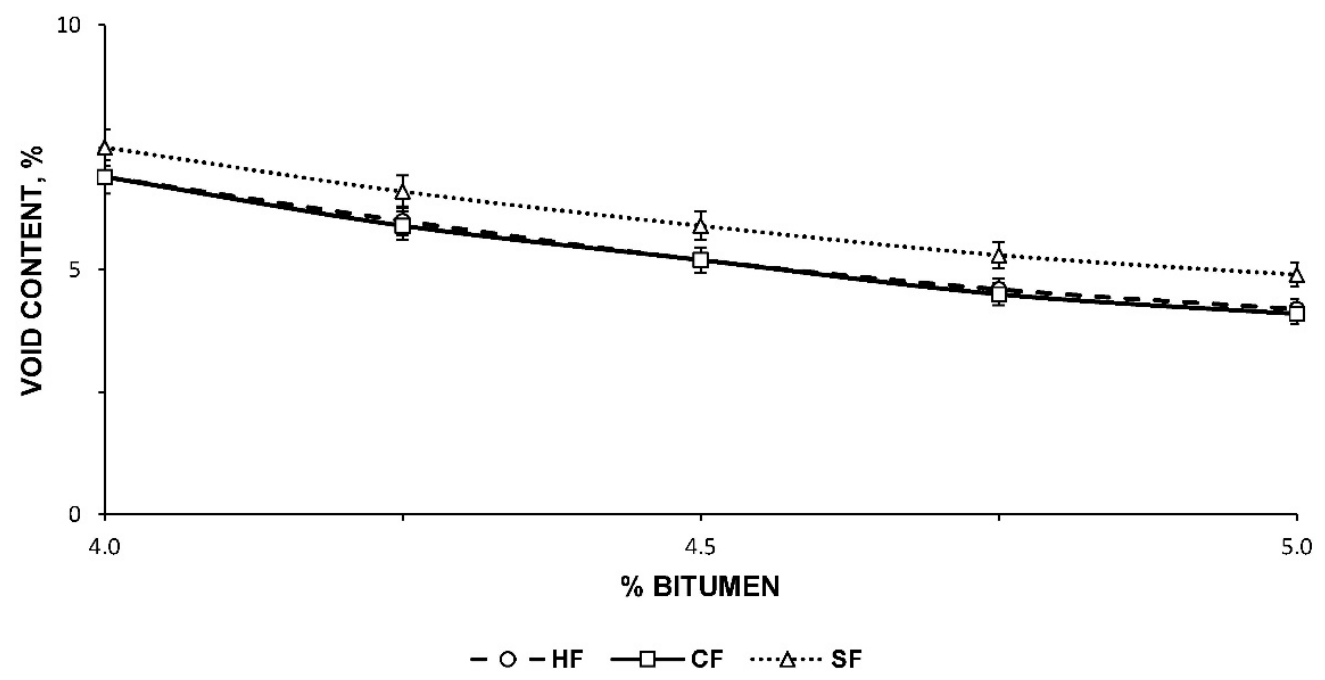

Figure 7. Void content of the HF, CF and SF families of bituminous mixtures as a percentage of bitumen.

It is easy to see how the families of bituminous mixtures blended with ladle furnace slag filler had a higher void content than the families blended with calcareous and hornfels filler. This higher void content is a positive factor for the bituminous mix, provided that good mechanical resistance is obtained. A higher voids content has a significant influence on a higher surface roughness and consequently in a safer pavement. In addition, the higher content of interconnected voids within the asphalt matrix provides greater drainage of the wearing course, preventing the accumulation of water on the surface. Furthermore, a high content of voids facilitates greater noise absorption due to the contact between tyre and pavement. Therefore, it is desirable to have a high voids content, because it gives the pavement the mentioned characteristics, provided that adequate resistances are obtained in the bituminous mix.

For the evaluation of mechanical resistance, and more specifically the suitability of bituminous mixtures for plastic deformation, the Marshall test was carried out. The Marshall test evaluates through resistance the optimal percentage of binder that does not provide plastic deformation of the pavement after its execution. These plastic deformations are essential in mixtures with continuous grading and low voids content, as they could cause total failure of the pavement if not taken into account. Therefore, the results of the Marshall test are reflected in Figure 8 for the different types of bituminous mixtures.

The Marshall stability of the families blended with ladle furnace slag as filler was superior to the families of mixtures blended with hornfels filler and calcareous filler. This test therefore reflects the good combination of bitumen with ladle furnace slag to conform a quality mastic able to withstand traffic loads at high temperatures and consequently to avoid the formation of plastic deformations. This high Marshall stability, in comparison with the other families of test specimens, also showed adequate cementitious behaviour of the ladle furnace slag, capable of providing the mix with better mechanical behaviour. 
FORCE VS. \% BITUMEN

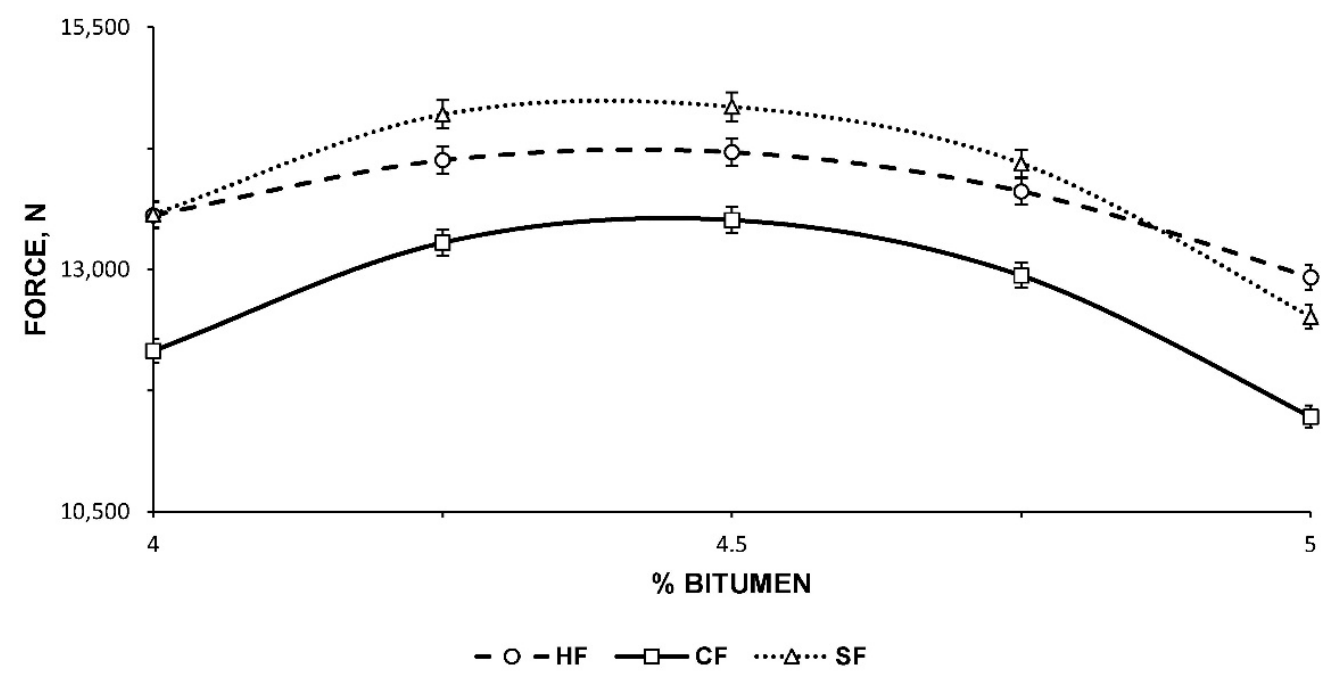

Figure 8. Marshall stability of the HF, CF and SF families of bituminous mixtures according to bitumen percentage.

In turn, the Marshall test allowed the deformation of bituminous mixtures to be evaluated, thus determining the probability of the creation of irregularities in the pavement due to deformation. Low deformation would represent a rigid pavement with little capacity for deformation that would end up cracking due to the continuous movement of vehicles. In turn, a high Marshall deformation would imply a pavement prone to the formation of irregularities in the pavement and, in short, the loss of safety and comfort of the road. The Marshall deformations of the three families of bituminous mixtures with the different fillers are detailed in Figure 9.

DISPLACEMENT VS. \% BITUMEN

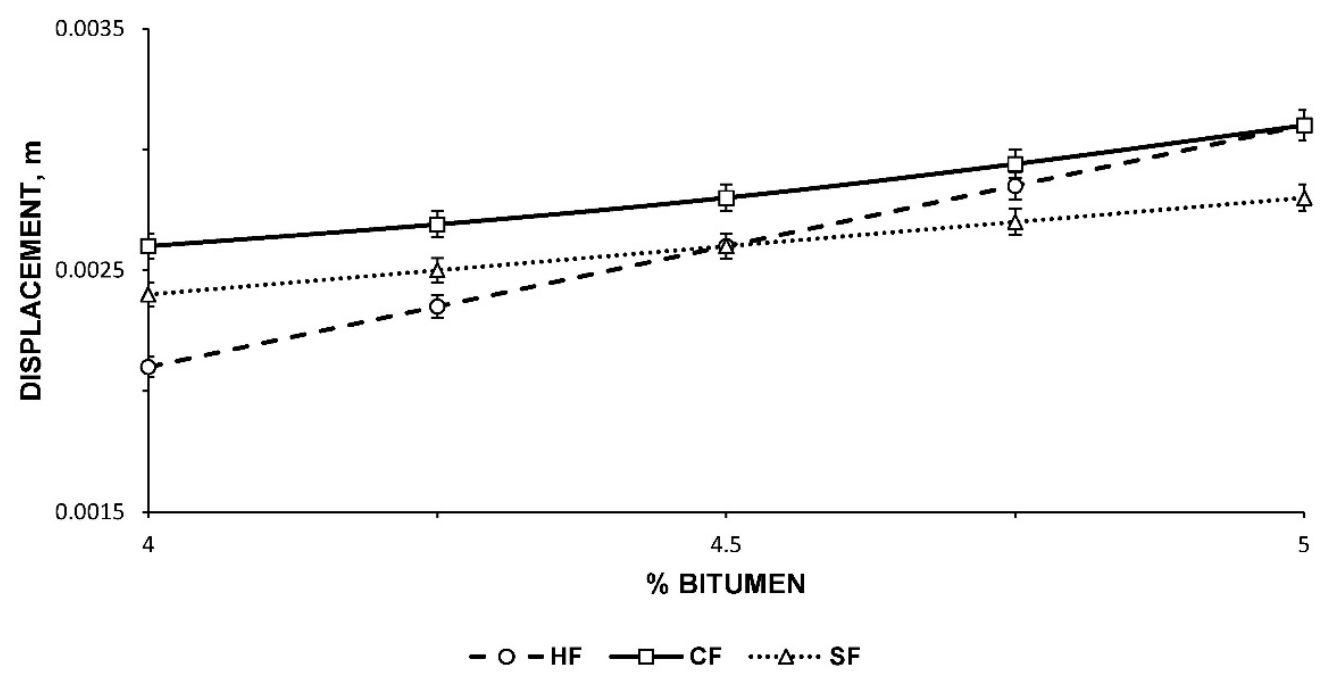

Figure 9. Marshall deformation of the HF, CF and SF families of bituminous mixtures according to the percentage of bitumen.

As can be seen in Figure 9, the deformation of the samples blended with ladle furnace slag is less than the deformation of the families blended with calcareous filler and, at the same time, much more stable than the deformations of the bituminous mixtures blended with hornfels filler. However, the values obtained of Marshall deformation for the three families and in all percentages of bitumen were adequate according to Spanish standards. 


\subsection{Determination of Optimal Material Combinations}

After evaluating the physical and mechanical properties of all the families of bituminous mixtures blended with different percentages of bitumen in the mix, the optimum percentage of bitumen was selected for each bituminous mixture. The optimum bitumen percentage was selected as the one that provided the greatest Marshall stability, as this is the fundamental test in these types of bituminous mixes. This is because the Marshall test evaluates the formation of plastic deformation through strength, thus avoiding the development of this problem, which would make the use of the bituminous mix impossible. However, it should be noted that the percentage of bitumen that provided the maximum Marshall resistance was selected as long as the results of the physical properties were acceptable.

The optimum bitumen percentages after analysing the Marshall graph, as seen in Figure 8 , were determined to be in the region of $4.5 \%$ for the three families. Given that the variation with respect to this percentage was infrequent and the variation of the minimum optimum properties, the percentage of $4.5 \%$ was selected as optimum for the three families, thus facilitating the proportioning. Subsequently, samples were made again according to the method described in the methodology, and the physical and mechanical tests were repeated, thus confirming the results obtained previously. The results of the optimal combination of materials for the three families are detailed in Table 6.

Table 6. Physical and mechanical properties of the HF, CF and SF families of bituminous mixtures blended with the optimum combination of materials.

\begin{tabular}{ccccc}
\hline Test & Standard & HF & CF & SF \\
\hline \% of bitumen in the mix & - & 4.5 & 4.5 & 4.5 \\
Bulk density, $\mathrm{kg} / \mathrm{m}^{3}$ & UNE-EN 12697-6 & $2439 \pm 61$ & $2430 \pm 72$ & $2428 \pm 75$ \\
Maximum density, kg/m $\mathrm{m}^{3}$ & UNE-EN 12697-5 & $2570 \pm 66$ & $2566 \pm 81$ & $2583 \pm 89$ \\
Void content, \% & UNE-EN 12697-8 & $5.1 \pm 0.1$ & $5.3 \pm 0.2$ & $6 \pm 0.2$ \\
Marshall Stability, N & UNE-EN 12697-14 & $14,203 \pm 517$ & $13,516 \pm 344$ & $14,691 \pm 509$ \\
Marshall Deformation, mm & UNE-EN 12697-14 & $0.0025 \pm 0.0001$ & $0.0027 \pm 0.0001$ & $0.0026 \pm 0.0001$ \\
\hline
\end{tabular}

As can be seen in Table 6, bituminous mixtures blended with ladle furnace slag filler had a higher percentage of voids, which gave the bituminous mixture special characteristics. At the same time, the Marshall stability was greater, ensuring good behaviour in the face of plastic deformation.

In addition to the tests mentioned, the immersion-compression test was carried out for the families of bituminous mixtures detailed with the three fillers mentioned, reflecting the results shown in Figure 10.

The immersion-compression test determined that the maximum resistance to simple compression without immersion corresponded to the family of bituminous mixtures that incorporated ladle furnace slag as filler. In addition, this family showed superior results in resistance to the simple compressive strength after immersion with respect to the other two families blended with calcareous filler and hornfels filler, reflecting a percentage of conserved strength greater than $75 \%$. It was thus stated that the effect of water on the cohesion of the bituminous mixtures was lower in mixtures made with ladle furnace slag and that, therefore, the compatibility of bitumen with the slag was higher. This fact corroborates the claimed cementitious characteristics of ladle furnace slag. 


\section{IMMERSION-COMPRESSION TEST}

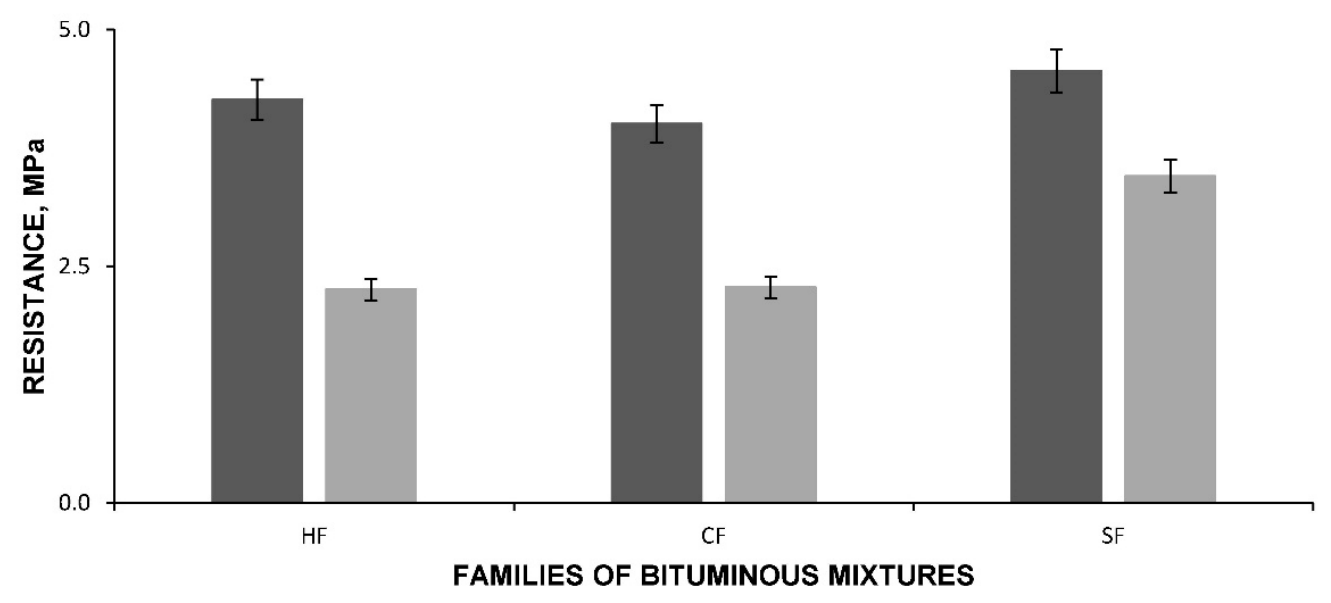

aRESISTANCE WITHOUT IMMERSION —RESISTANCE WITH IMMERSION

Figure 10. Immersion-compression test for the optimum combination of materials from the HF, CF and SF bituminous mix families.

\section{Conclusions}

The results of the different tests reflected in the previous sections conclude with confirmation of the initial hypothesis. To corroborate this hypothesis, the partial conclusions derived from this investigation are detailed below:

- The ladle furnace slag has a low percentage of carbon and hydrogen, demonstrating the absence of organic matter. The main chemical elements are calcium, magnesium, silicon, aluminium and iron, combined in chemical compounds such as calcite, olivine, periclase and calcium or magnesium silicates. Consequently, this chemical composition is responsible for the cementitious properties of the slag, with no potentially toxic elements present in high proportion.

- Ladle furnace slag has a particle density and bulk density similar to that of natural aggregate, with no plasticity and a very small particle size ideal for use as a filler.

- Bituminous mixtures made with ladle furnace slag filler show a higher Marshall stability than other families of mixtures with different fillers, obtaining a higher void content and similar plastic deformation.

- The optimum percentage of bitumen for the three families is similar, with this percentage being $4.5 \%$ of the mixture. It is this percentage of bitumen that provides the greatest Marshall stability for the three families of mixes.

- The simple compression test without immersion showed better results for bituminous mixtures blended with ladle furnace slag. In turn, the resistance after immersion was also higher in this family, representing a greater compatibility of the slag with the bitumen than the other fillers.

On the basis of the partial conclusions obtained, it can be stated that the use of ladle furnace slag in continuous grading hot mix asphalt gives the final bituminous mix superior physical and mechanical properties to the fillers traditionally used. In other words, the use of this waste not only makes it possible to obtain products of similar quality but also improves the properties. It is, therefore, a clear example of the goodness of the application of the new criteria of the circular economy.

Author Contributions: Conceptualization, F.J.N.-R., F.A.C.-I., E.R.M.-L., J.M.T.-S., J.S.-M. and C.M.-G.; methodology, F.J.N.-R., F.A.C.-I., E.R.M.-L., J.M.T.-S., J.S.-M. and C.M.-G.; software, J.M.T.-S. and J.S.-M.; validation, F.A.C.-I. and E.R.M.-L.; formal analysis, F.A.C.-I. and E.R.M.-L.; investigation, F.J.N.-R., J.M.T.-S. and J.S.-M.; resources, F.A.C.-I. and C.M.-G.; data curation, E.R.M.-L. and C.M.-G.; writing - original draft preparation, F.J.N.-R. and J.S.-M.; writing—review and editing, J.M.T.-S. and C.M.-G.; visualization, F.J.N.-R. and J.M.T.-S.; supervision, F.A.C.-I.; project administration, J.S.-M. 
and C.M.-G.; funding acquisition, F.A.C.-I. All authors have read and agreed to the published version of the manuscript.

Funding: This research received no external funding.

Institutional Review Board Statement: Not applicable.

Informed Consent Statement: Not applicable.

Data Availability Statement: Data is contained within the article.

Acknowledgments: The technical and human support provided by CICT of Universidad de Jaén (UJA, MINECO, Junta de Andalucía, FEDER) is gratefully acknowledged.

Conflicts of Interest: The authors declare no conflict of interest.

\section{References}

1. Plati, C. Sustainability factors in pavement materials, design, and preservation strategies: A literature review. Constr. Build. Mater. 2019, 211, 539-555. [CrossRef]

2. Shi, X.; Mukhopadhyay, A.; Zollinger, D.; Grasley, Z. Economic input-output life cycle assessment of concrete pavement containing recycled concrete aggregate. J. Clean. Prod. 2019, 225, 414-425. [CrossRef]

3. Arabani, M.; Azarhoosh, A.R. The effect of recycled concrete aggregate and steel slag on the dynamic properties of asphalt mixtures. Constr. Build. Mater. 2012, 35, 1-7. [CrossRef]

4. Simone, A.; Vignali, V.; Lantieri, C. A new "frugal" approach to road maintenance: $100 \%$ Recycling of a deteriorated flexible pavement. In Proceedings of the 7th International Conference on Maintenance and Rehabilitation of Pavements and Technological Control, MAIREPAV, Auckland, New Zealand, 28-30 August 2012.

5. Morseletto, P. Targets for a circular economy. Resour. Conserv. Recycl. 2020, 153, 104553. [CrossRef]

6. Demirbas, A. Waste management, waste resource facilities and waste conversion processes. Energy Convers. Manag. 2011, 52, 1280-1287. [CrossRef]

7. Anthonissen, J.; Van den bergh, W.; Braet, J. Review and environmental impact assessment of green technologies for base courses in bituminous pavements. Environ. Impact Assess. Rev. 2016, 60, 139-147. [CrossRef]

8. Zheng, X.; Easa, S.M.; Ji, T.; Jiang, Z. Incorporating uncertainty into life-cycle sustainability assessment of pavement alternatives. J. Clean. Prod. 2020, 264, 121466. [CrossRef]

9. Menaria, Y.; Sankhla, R. Use of Waste Plastic in Flexible Pavements-Green Roads. Open J. Civ. Eng. 2015, 5, 299-311. [CrossRef]

10. Al-Busaltan, S.; Al Nageim, H.; Atherton, W.; Sharples, G. Green Bituminous Asphalt relevant for highway and airfield pavement. Constr. Build. Mater. 2012, 31, 243-250. [CrossRef]

11. Jin, R.; Li, B.; Zhou, T.; Wanatowski, D.; Piroozfar, P. An empirical study of perceptions towards construction and demolition waste recycling and reuse in China. Resour. Conserv. Recycl. 2017, 126, 86-98. [CrossRef]

12. Lokesh, Y. Study On the Effect of Stone, Dust, Ceramic Dust and Brick Dust as Fillers on the Strength, Physical and Durability Properties of Bituminous Concrete (BC-II) Mix. Int. J. Appl. Eng. Res. 2018, 13, 203-208.

13. Mistry, R.; Kumar Roy, T. Performance evaluation of bituminous mix and mastic containing rice husk ash and fly ash as filler. Constr. Build. Mater. 2020, 268, 121187. [CrossRef]

14. Zakaria, N.M.; Hassan, M.K.; Ibrahim, A.N.H.; Rosyidi, S.A.P.; Yusoff, N.I.M.; Mohamed, A.A.; Hassan, N. The use of mixed waste recycled plastic and glass as an aggregate replacement in asphalt mixtures. J. Teknol. 2018, 80, 79-88. [CrossRef]

15. Sangiorgi, C.; Lantieri, C.; Dondi, G. Construction and demolition waste recycling: An application for road construction. Int. J. Pavement Eng. 2015, 16, 530-537. [CrossRef]

16. Fakhri, M.; Javadi, S.; Sedghi, R.; Arzjani, D.; Zarrinpour, Y. Effects of deicing agents on moisture susceptibility of the WMA containing recycled crumb rubber. Constr. Build. Mater. 2019, 227, 116581. [CrossRef]

17. Gala, A.; Guerrero, M.; Serra, J.M. Characterization of post-consumer plastic film waste from mixed MSW in Spain: A key point for the successful implementation of sustainable plastic waste management strategies. Waste Manag. 2020, 111, 22-33. [CrossRef]

18. Yan, J.; Karlsson, A.; Zou, Z.; Dai, D.; Edlund, U. Contamination of heavy metals and metalloids in biomass and waste fuels: Comparative characterisation and trend estimation. Sci. Total Environ. 2020, 700, 134382. [CrossRef]

19. Chu, L.; He, W. Toxic metals in soil due to the land application of sewage sludge in China: Spatiotemporal variations and influencing factors. Sci. Total Environ. 2020, 757, 143813. [CrossRef]

20. Escorias de Acería de Horno de Arco Eléctrico /CEDEX. 2013. Available online: http://www.cedexmateriales.es/catalogo-deresiduos/25/escorias-de-aceria-de-horno-de-arco-electrico/ (accessed on 31 October 2020).

21. Sideris, K.K.; Tassos, C.; Chatzopoulos, A.; Manita, P. Mechanical characteristics and durability of self compacting concretes produced with ladle furnace slag. Constr. Build. Mater. 2018, 170, 660-667. [CrossRef]

22. Herrero, T.; Vegas, I.J.; Santamaría, A.; San-José, J.T.; Skaf, M. Effect of high-alumina ladle furnace slag as cement substitution in masonry mortars. Constr. Build. Mater. 2016, 123, 404-413. [CrossRef] 
23. Sáez-De-Guinoa Vilaplana, A.; Ferreira, V.J.; López-Sabirón, A.M.; Aranda-Usón, A.; Lausín-González, C.; Berganza-Conde, C.; Ferreira, G. Utilization of Ladle Furnace slag from a steelwork for laboratory scale production of Portland cement. Constr. Build. Mater. 2015, 94, 837-843. [CrossRef]

24. Adolfsson, D.; Engström, F.; Robinson, R.; Björkman, B. Cementitious Phases in Ladle Slag. Steel Res. Int. 2011, 82, 398-403. [CrossRef]

25. Shi, C. Characteristics and cementitious properties of ladle slag fines from steel production. Cem. Concr. Res. 2002, 32, 459-462. [CrossRef] 